\title{
Experience the magic of light and color: outreach activity by Universidad del Valle student chapter
}

Claudia Valdes, Camilo Reyes, Alberto Osorio, Efrain Solarte

Claudia Valdes, Camilo Reyes, Alberto Osorio, Efrain Solarte, "Experience the magic of light and color: outreach activity by Universidad del Valle student chapter," Proc. SPIE 7783, Optics Education and Outreach, 77830F (30 August 2010); doi: 10.1117/12.861135

SPIE Event: SPIE Optical Engineering + Applications, 2010, San Diego, California, United States 


\title{
Experience the magic of light and color: Outreach activity by Universidad del Valle student chapter
}

\author{
Claudia Valdes*, Camilo Reyes, Alberto Osorio, Efrain Solarte \\ Quantum Optics Group, Universidad del Valle, A.A. 25360, Cali, Colombia
}

\begin{abstract}
During 2007, the Universidad del Valle Student Chapter presented a proposal for developing an educational outreach activity for children from an underprivileged zone to the Optical Society of America Foundation (OSAF) and to SPIE. The activity was carried out jointly by OSA and SPIE Universidad del Valle Student Chapters in the hillsides of Santiago de Cali, in a zone known as "Pueblo Joven" during 2008. It was aimed to boys and girls with ages between 8 and 13 years and was called "Experience the magic of light and color". The main purpose was to bring the children some basic concepts on optics and to encourage them to explore science through optics. The Universidad del Valle Student Chapters designed a series of talks and practical workshops where children participated in hands-on experiments that easily explain the fundamental concepts of light phenomena. Afterwards the children presented their achievements in a small science fair offered to the community and tried to explain in their own words what they learned and built. In this work, we present the most successful experimental designs and the educational standards we tried to develop with this activity.
\end{abstract}

Keywords: Outreach activity, Student chapter, Hands-on experiments, Optics dissemination

\section{INTRODUCTION}

In 2003, students of the Quantum Optics Group at Universidad del Valle decided to form a group that gave rise to the first Student Chapter in Colombia affiliated to an international society of Optics, in this case to the Optical Society of America, OSA. Later in 2006, motivated by the benefits offered by SPIE, the Universidad del Valle SPIE student Chapter was created. Both Chapters share their main aims: to promote and disseminate knowledge of Optics within the academic and local communities, and contribute to the professional development of its members; and for this reason, since 2007 they decided to join efforts and proposed as main activity of the Chapters the design and development of an outreach activity devoted to children in an underprivileged area.

The proposed activity consists of a Workshop on Optics designed to inspire and encourage these children to approach science using low-cost experiments, which easily explain some basic concepts about Optics and light behavior. This proposal was positively accepted by both societies, resulting in the approval of the activity Grant, which can be requested annually to SPIE, in addition to the award with one of the grants for educational outreach activities of Optics, assigned by the Foundation of the American Society of Optics (OSAF), for which proposals from OSA Student Chapters around the world participate twice a year.

The area where the activity took place, known as "Pueblo Joven" (New Town in English), is located on the hillsides of the city of Santiago de Cali. The development of this workshop was made possible through contact with students of Sociology at the Universidad del Valle, who lead in this place a community center named "Centro Cultural La Red", CCR. Throughout the year, this center is mainly dedicated to promote cultural, artistic, recreational and technical activities, as well as sports, opening doors to progress for people in their community. In this particular occasion, this center allowed the Universidad del Valle OSA and SPIE student Chapters (CUVO), to give their children the opportunity to meet face to face with Science and to enjoy an activity different to those previously offered at the center. For this purpose we designed an activity consisting on a series of explanatory talks accompanied by practical developments about concepts and phenomena related to the behavior of light.

* claupvaldes@gmail.com; phone 572 339-4610; fax 572 339-3237

Optics Education and Outreach, edited by G. Groot Gregory, Proc. of SPIE Vol. 7783,

77830F · @ 2010 SPIE · CCC code: 0277-786X/10/\$18 - doi: 10.1117/12.861135 


\section{DESIGN AND DESCRIPTION OF THE EXPERIMENTS}

Taking into account the population of children in the community, it was decided that the workshop on Optics would target boys and girls aged between eight to thirteen years and no previous knowledge in reading or math was required for their participation. Having determined what would be the auditorium, members of CUVO began the stage of selection, design and testing of selected experiments.

For the selection stage, experiments employing low-cost materials were preferred, this with the intention of allowing children to easily reproduce them. Besides, for every experiment that passed the tests, we produced a modular design to facilitate the construction of the apparatus and to minimize the construction time during the workshop. Under these conditions, the experiments to be undertaken by children would be a kaleidoscope, a periscope, Newton's disk, the solar oven, microscope, and a photosensor.

Several of these experiments required a power source, so we designed and produced a voltage source to fill all these requirements. Moreover, some experiments were planned for exhibition in order to illustrate the physiology and optics of the eye; the phenomena of refraction, fluorescence, scattering, dispersion and propagation of light.

The following is a brief description of the experiments developed in the workshop:

\subsection{Kaleidoscope}

This device has the same operating principle of a conventional kaleidoscope, with the difference of using a rotating picture to form images ${ }^{1,2,3}$. It is composed by three mirrors arranged in a prism with reflective side inwards. We created a base for the kaleidoscope, so the picture could be born in the back using a pin to allow its rotation like seen on Figure 1 (left). Even the device can be left open to allow the entry of any image of nature and get a myriad of shapes.

From the optical point of view, this experiment is useful to show younger children that the light reflects in the mirrors and in other surfaces ${ }^{4}$. To older children it could be explained that light interacts with matter and that in this case the process is called reflection. Moreover, with the objective of explaining why the observed shapes appear, it is necessary to introduce that reflection angle of the beam is the same as that of the incident beam ${ }^{4}$. The kaleidoscope can also help teach the concept of rotational symmetry ${ }^{5}$.
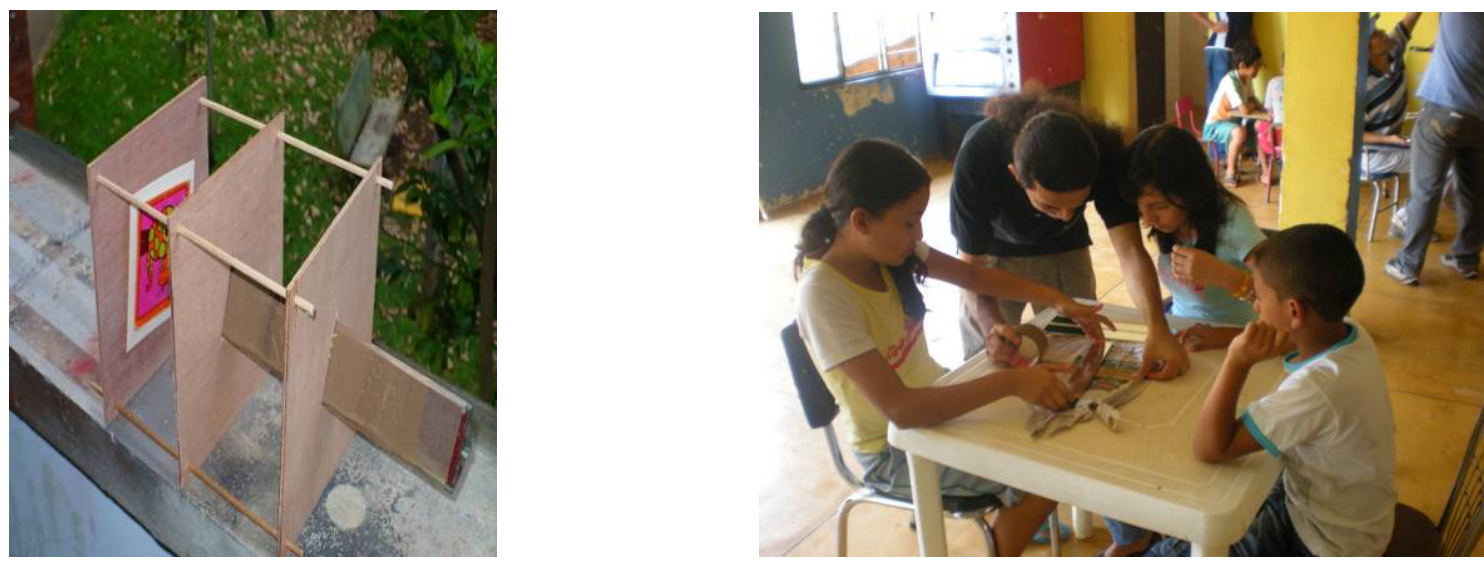

Figure 1. Prototype of the kaleidoscope constructed by CUVO members (left) and children assembling this device during the workshop (right).

\subsection{Periscope}

This instrument allows observing objects that are not located in a direct line of vision. We chose this apparatus because it let illustrate that light travels following a straight line until it reaches an object or until it passes from one medium to another ${ }^{6,7,8}$.

Once again, the understanding of reflection laws and phenomenon is reinforced. It is also possible to introduce the description of light as rays, which is the principle of geometrical optics. This instrument shows how mirrors and certain light properties can be used to create novel objects that are the basis of several technical designs. The assembly of this device can show that placing the mirrors with a correct inclination angle plays a main role in the proper functioning of it. 

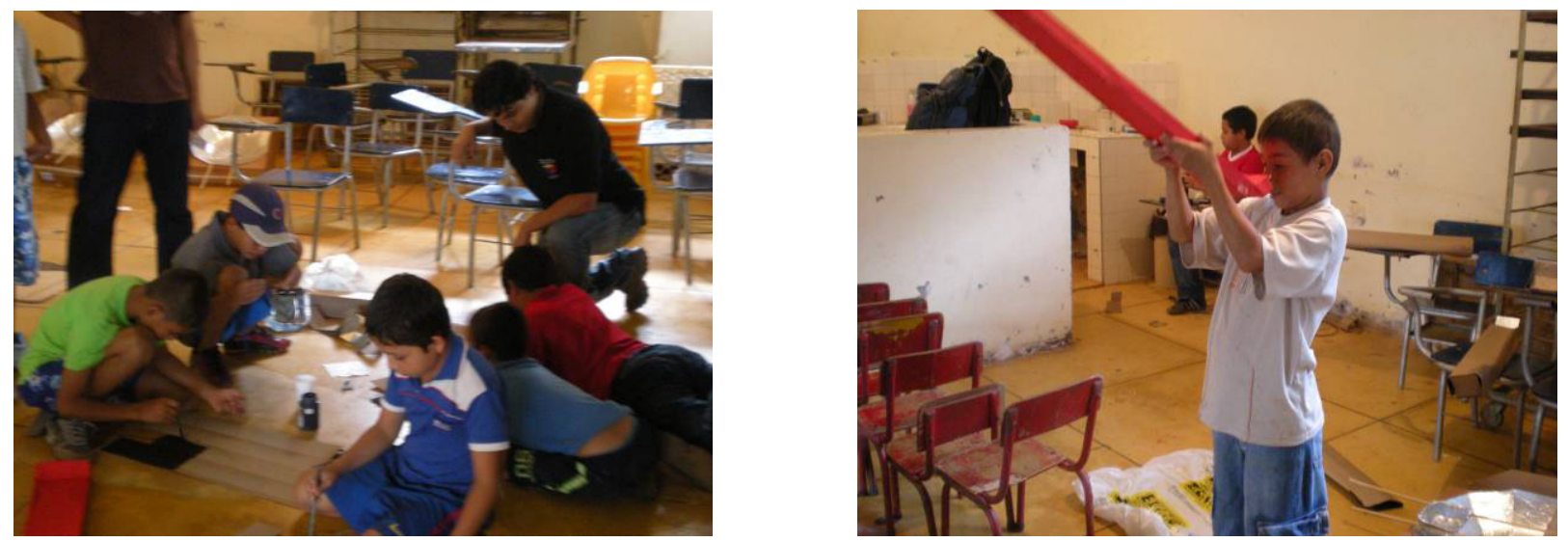

Figure 2. Assembly and test of the periscope built by children at CCR.

\subsection{Solar stove}

We constructed a parabolic solar mirror using a cardboard armature covered with kitchen aluminum foil (Figure 3) and then it was mounted on a hard cardboard box 9 . The operation of this device is based again on the laws of light reflection, but this time on a concave mirror of parabolic shape. Using geometrical optics, it is possible to explain that solar light rays are reflected and focused by the mirror in a single point, were the piece to be heated is placed. Furthermore, this experiment is useful to show that light transports energy and that in this particular case, it is transformed in calorific energy ${ }^{4}$.
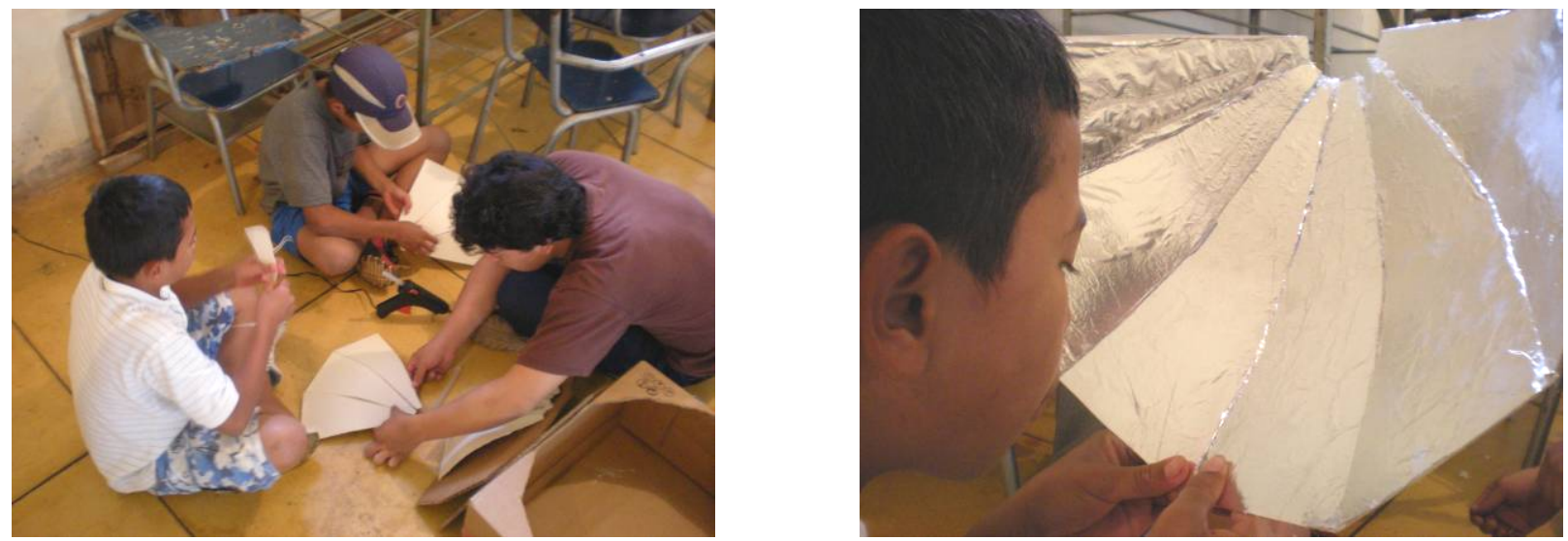

Figure 3. Children working on the construction of the solar stove's parabolic mirror.

\subsection{Newton's Disk}

This experiment consists of a cardboard disc, painted on one side with the seven easily distinguishable colors in the visible spectrum and which is placed on a rotating disk driven by a motor. When the disk rotates it turns white, which helps explain that white light is composed of other colors that are fundamental or pure, and in that sense, can be taken as the inverse of light dispersion experiment through a prism. For the younger children, the idea of this experiment is to explain them that there are certain "pure" colors and that they can be combined to give rise to other colors. Here it is possible to let the children paint the disc with the colors they wish and depending on how the disc was divided, equally or not, they could observe that mixed colors also depend on how much is the contribution of each pure color, giving with this a basic idea about spectroscopy. For older children this experiment would explain the same idea in a more elaborate way, trying to include the concepts of wavelength and intensity ${ }^{10}$. The construction and function of this device is shown in Figure 4 (left). 

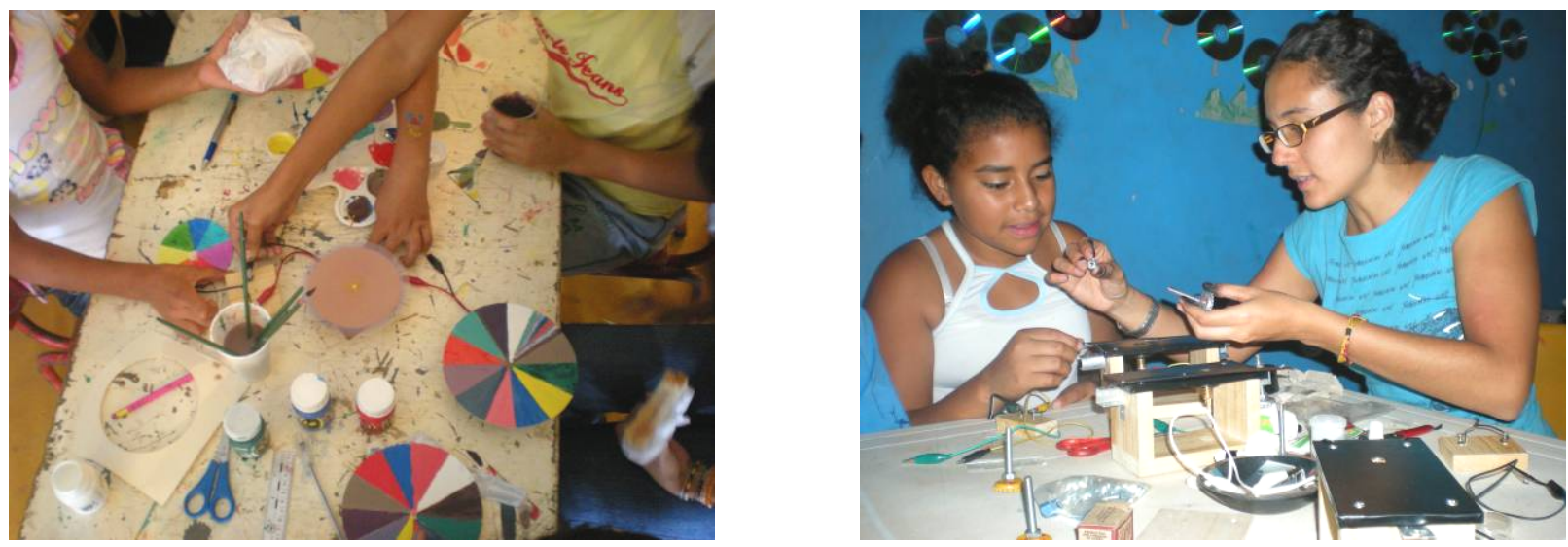

Figure 4. Workspace for the creation of Newton's disks (left) and the assembly of the microscopes (right).

\subsection{Microscope}

A very small glass sphere was used to build a single lens microscope, model of the microscope designed by Leeuwenhoek. The sphere was glued onto a pinhole in a steel plate suspended by a wooden frame allowing the lens movement by means of some screws. This movement allows focusing correctly on the sample ${ }^{11}$.

This instrument was included to show children some objects that con not be seen with naked eye such as microorganisms in a drop of water, red blood cells and the structure of human hair. With a microscope it is possible to explain lens properties and the principles on image formation. In addition, we intend to show the differences between macroscopic and microscopic observations, the existence of a microscopic reality present in physical, chemical and biological phenomena and objects, and the need and importance of amplifying the reach of our senses and to have an observational access to the microscopic world.

\subsection{Photosensor}

A prototype of automatic light switch was constructed using a photoresistor. This circuit was designed to show how light could be used to command some devices. As an example, it is useful to remind about the circuits that control lighting in cities, which as soon as they no longer receive certain intensity of sunlight, they turn on automatically. With this experiment, children can see that light has electrical effects; they can check the rectilinear propagation of light rays and can play with the device while realizing about the speed of light through the optical system response. The development of this circuit was made by children over 10 years.
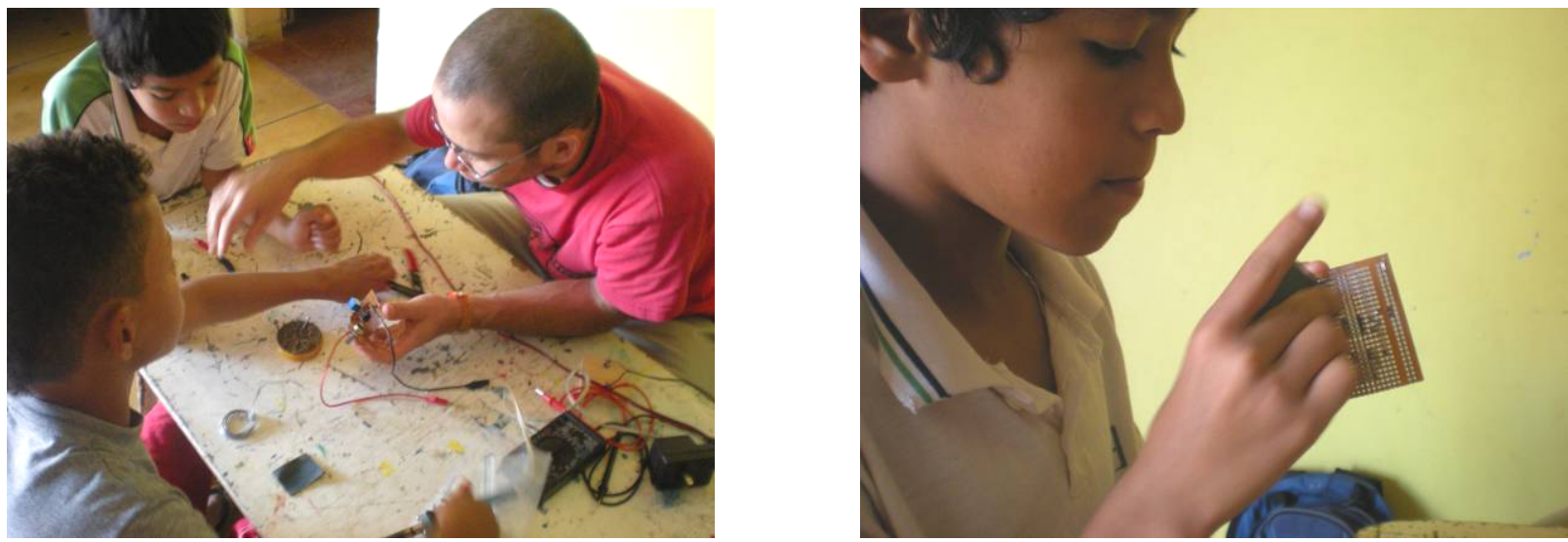

Figure 5. One of the chapter members explaining how to build the photosensor circuit (left) and a participant following instructions. 


\section{ACTIVITY DEVELOPMENT}

We planned a program of short talks and practical workshops, and we designed a series of experiments to explain some fundamental phenomena of light in a simple way. During the talks, we presented some experiments to illustrate a concept explained so that children could grasp it easily through a visual experience. The other part of the activity, and the most amazing for children, was allowing them to interact directly with the Optics and Science through the assembly and operation of homemade experiments. They were allowed to cut, paste, paint the parts and play with the instruments. At the end of the activity, the children presented their experiments on a small science fair with an explanation, in their own words, about what they understood in relation to the optical phenomenon present in every experience, thereby contributing to the strengthening of the scientific concepts involved.
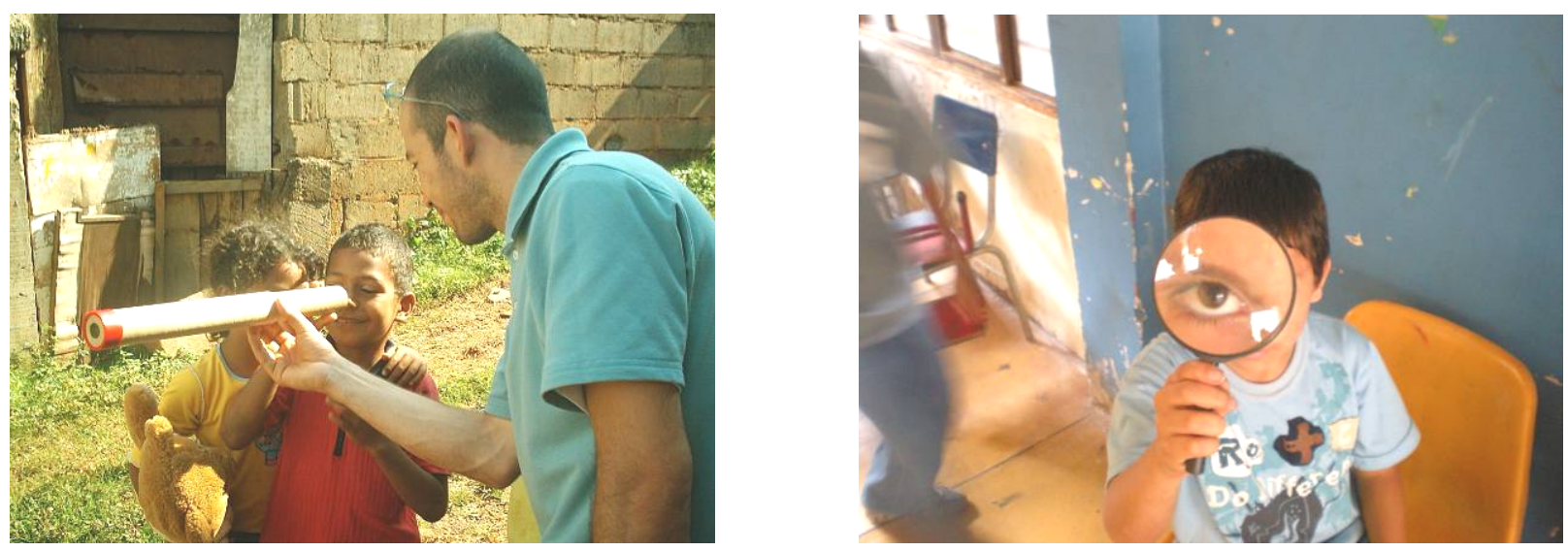

Figure 6. Children using a small telescope and a big lense provided to the Chapter by SPIE and OSA.

This activity benefited about 35 people, including 28 children of the CCR. The workshop was divided into four sessions that took place on Saturday afternoons. The first day we held a socialization activity among children and members of CUVO. We made an introduction to optics and illustrated the main ideas of each experiment available for the practical workshop. Looking for some motivation on the children, experiment of fluorescence and other light phenomena were presented, using some materials available in the Optics Discovery Kit and in the Optical bag donated to our chapter by OSA and SPIE, as shown in Figure 6. We organized the workgroups to develop the experiments. The children were able to choose the experiments they wanted to work in, according to their age and the complexity of the device. Each child had the opportunity to work in two experiments under the supervision of CUVO members.
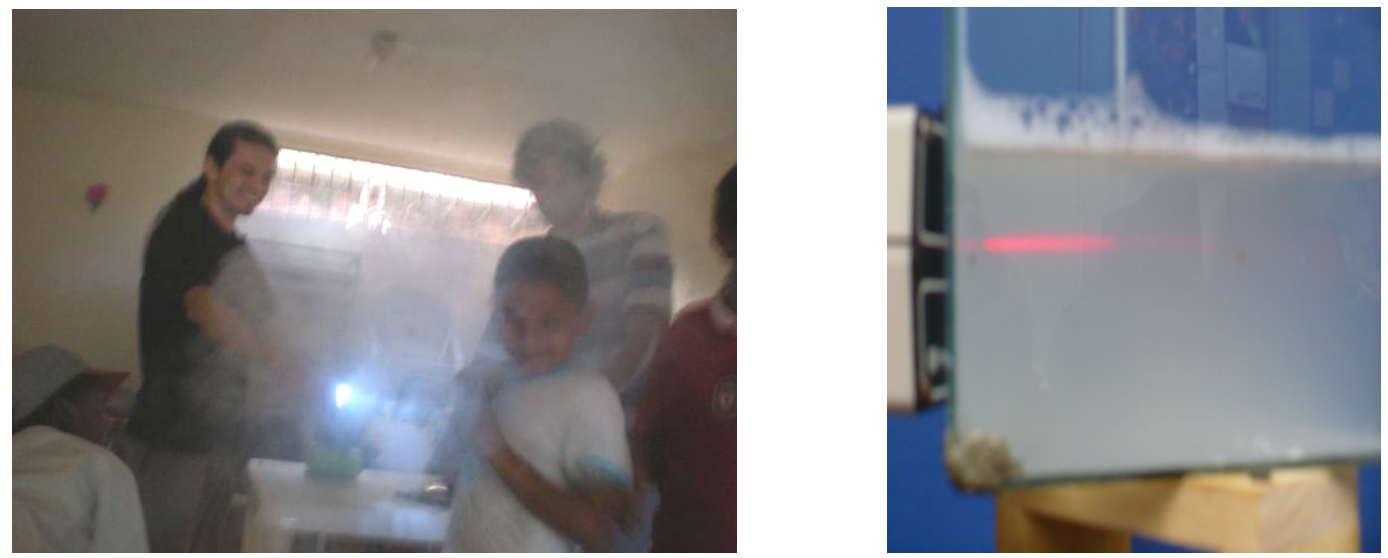

Figure 7. Explanation about light scattering in two different media using a white light and a laser. 
The main goal in the second session was to explain the phenomena of light propagation. The scattering of light when it propagates in a particular environment was showed. To produce the medium, a smoke machine was used and as light sources a common flashlight and a He-Ne laser were used, these being non-coherent light and coherent, respectively, to determine differences and similarities between the observed processes. These experiments are presented in Figure 7.

In the third session, a talk about the optics of human eye and its operation was done. Here the children witnessed the dissection of a cow's eye by one of the tutors to illustrate the anatomy of the eye as seen in Figure 8. Later, they worked on the experiments.
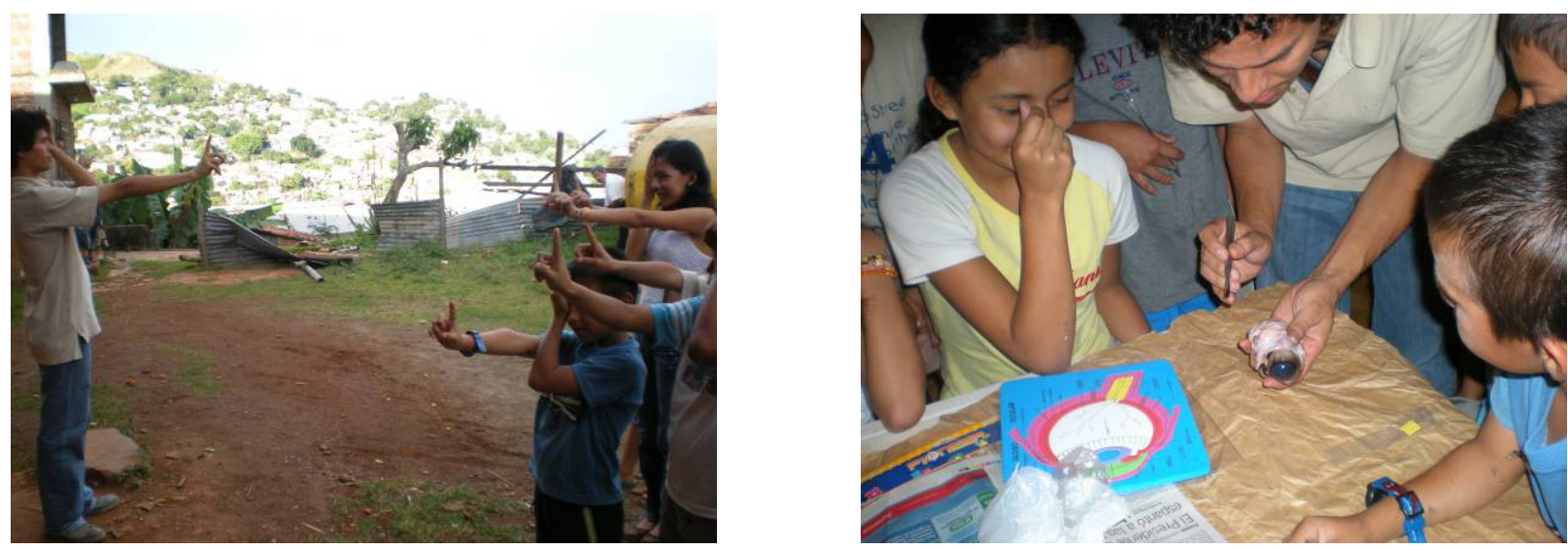

Figure 8. Presentation of the eye blind point (left) and cow's eye dissection (right).

A small Science Fair took place in the fourth session. Some parents attended and observed the work done by the children, showing a high level of satisfaction with the activity and its results.
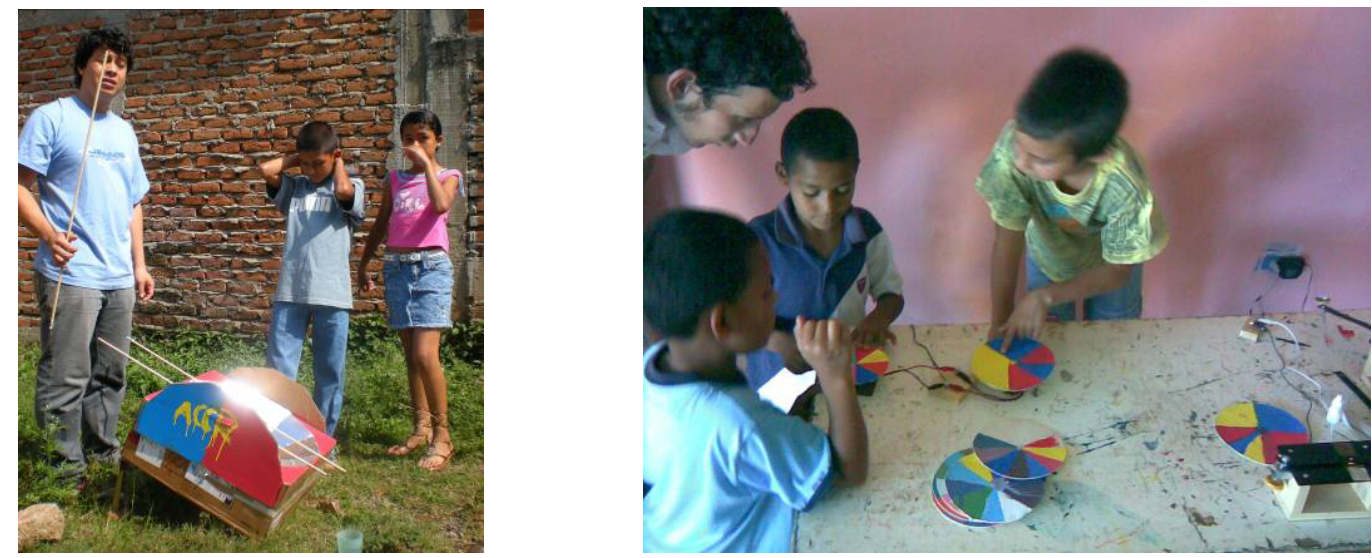

Figure 9. Solar stove functioning (left) and children explaining to an adult how a Newton's disk works (right) during the small Science Fair.

\section{ACTIVITY RESULTS AND CONCLUSIONS}

With this workshop, the participants had a completely new opportunity to experience Science through Optics. The children acquired basic ideas regarding to the phenomenology of optics and light behavior with didactical experiments capable of awaking concerns in them and of stimulating their creativity. The children were motivated in their scientific curiosity, even in an environment that does not foster this motivation. They showed their desire of exploring and forming their own ideas about Optics, according on what they could experiment. 
With this activity, we offered to this sector of our population the opportunity of approaching to Sciences in a fun way. In the future, this may increase chances for workshop participants to access a higher education level through a technical career, and why not, a scientific career.

At the end of the activity, the Student Chapter members expressed their satisfaction when they realized that the Chapter's outreach activities are not only intended for teaching Science and Optics, but that these activities can have a great social impact. For the future, there is the proposal of continuing with this kind of activities which can benefit other sectors in our city.

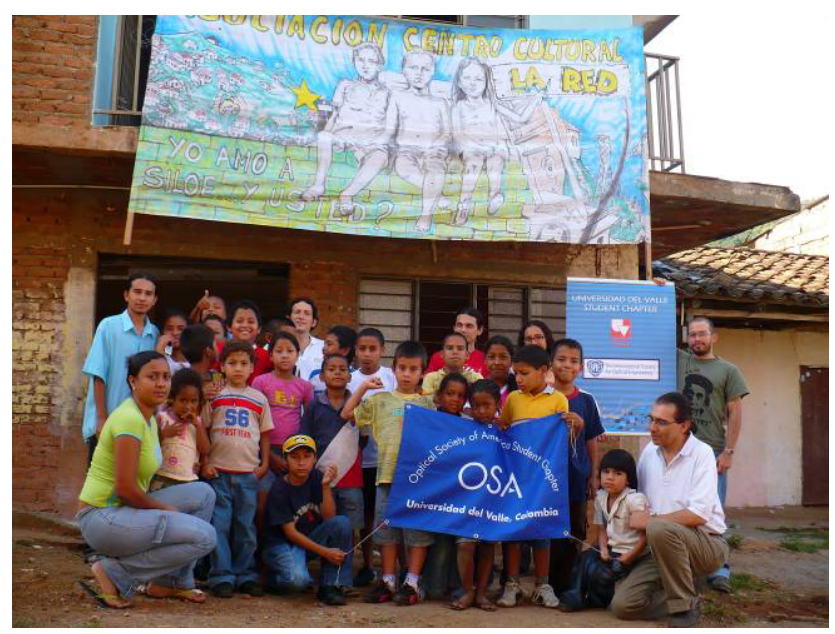

Figure 10. Photography with participants, CCR leaders and Chapter members at the end of the event.

\section{ACKNOWLEDGEMENTS}

Authors would like to thank to all Universidad del Valle Student Chapter members for their effort and support in the development and accomplishment of the activity, to OSA and SPIE for the financial support and to the leaders of the Cultural Center "La Red" for allowing us to work with the children in their community.

\section{REFERENCES}

[1] Suzuki, J., "Color Wheel Kaleidoscope A Simple Way to Make Beautiful Patterns", Resource Area for Teaching, San Jose, (2009).

[2] McMillan, B. A., "Kaleidoscopes and Design Technology in Grade 4", www.stam.mb.ca/Kaleidos4.pdf

[3] www.nbtc.cornell.edu/education/kitlib/getlessonplan.php?id=66

[4] Bruton, S., Ong, F., Geeting, G., [Science Content Standards for California Public Schools: Kindergarten through Grade Twelve], California Department of Education, Sacramento, (2000).

[5] Ong, F., Lucia, B., Yee, K., [Mathematics Content Standards for California Public Schools: Kindergarten through Grade Twelve], California Department of Education, Sacramento, (1999).

[6] www.wpi.edu/Images/CMS/PIEE/5f1.pdf

[7] www.sciencetoymaker.org/periscope/assembl.html

[8] www.micro.magnet.fsu.edu/optics/activities/students/scopes.html

[9] www.cie.unam.mx/ arp/solar1.html

[10] Flinn Scientific Inc.,"Newton's Color Wheels-Additive Color Mixing", Physical Science Activities, Flinn Scientific Inc., Publication No. 10473, Batavia, (2006).

[11] www.funsci.com/fun3 en/usph/usph.htm

[12] Bowman, D., Buckley, P. K., Francis, R. W., Suiter, K. A, [Scope It Out: Standards-Based Microscope Lessons for the Middle School], Eisenhower Regional Consortium for Mathematics and Science Education at AEL, Charleston, (1996). 